E

\title{
SECOND LATIN AMERICAN CONFERENCE ON PERSON CENTERED MEDICINE
}

\section{SCIENCE AND HUMANISM}
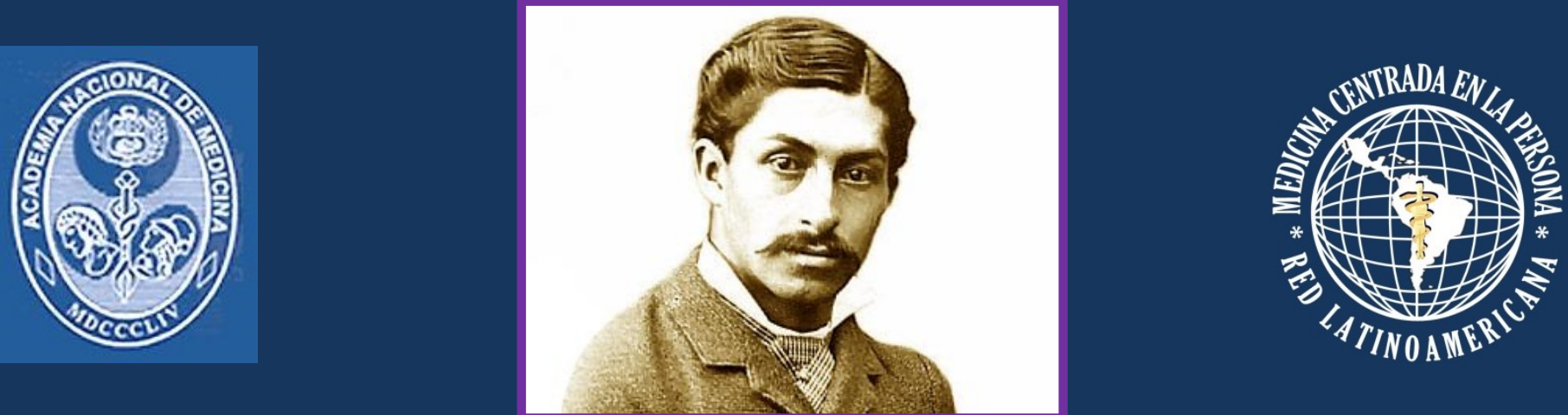

Daniel Alcides Carrión

Martyr of the Peruvian Medicine

LIMA, 16 AND 17 DECEMBER 2016

Conyention Center from the Medical College of Peru AY. 28 DE JULIO 776, MIRAFLORES

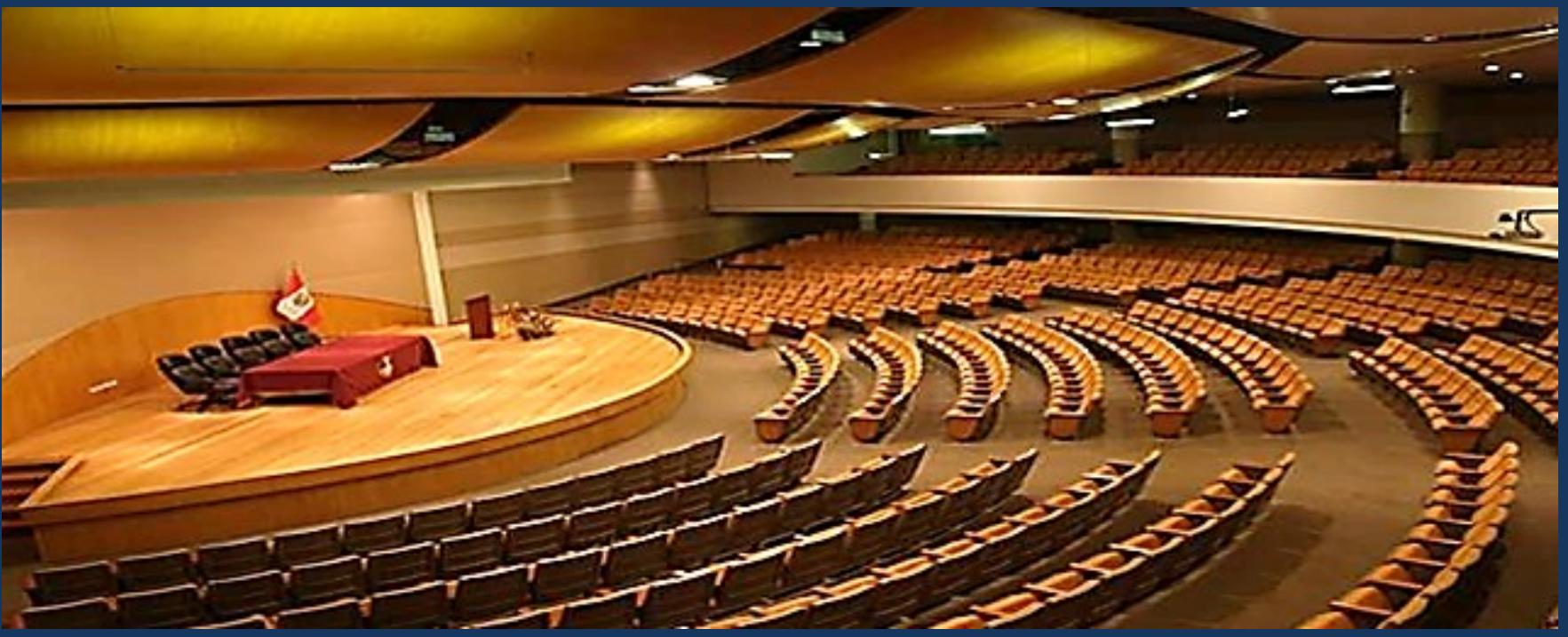

Are invited to participate all health professionals in Peru and Latin America Information and registration: Secretariat of the National Academy of Medicine Tel.: +511-652-3819 <academianacionaldemedicina@gmail.com>

Will be issued Certificates of Participation and Continuing Medical Education by the International

College of Person Centered Medicine, valid for Recertification by the Medical College of Peru.
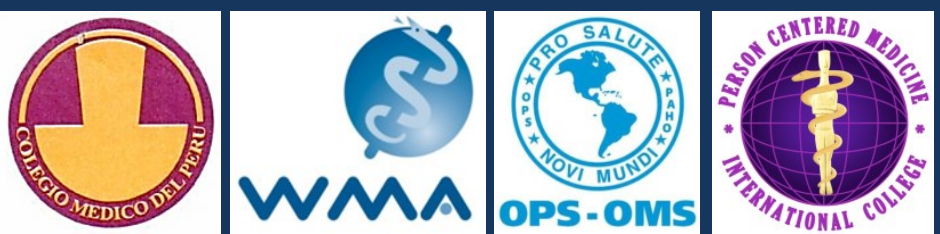


\section{FIRST DAY: FRIDAY, DECEMIER 26, 2016}

$\begin{array}{ll}\text { 8:00 - 9:00 } & \text { Registration } \\ \text { 9:00 - 9:40 } & \text { Opening }\end{array}$

Proscenium of Honor: Ministry of Health of Peru, Perwian National Academy of Medicine, Latin American Network of Person Centered Medicine, Medical College of Peru, National Institute of Health, San Marcos National University, Cayetano Heredia Perwian University, Santo Toribio of Mogrovejo Catholic University, World Medical Assocication, Pan American Health Organization / WHO, International College of Person Centered Medicine.

9:00 - 9:20 Welcoming words by the authorities in the Proscenium of Honor

9:20 - 9:40 Introduction to Science and Humanism in Person Centered Medicine in Latin America

\section{9:40 - 13:10 Session 1: Science and Humanism in Person Centered Health} Research

$9.40-10.00 \quad$ Presentation 1: Individualized genetic medicine and person centered medicine

$10.00-10.20 \quad$ Presentation 2: Person centered epidemiology of health

$10.20-10.40$ Presentation 3: Research in humanities and social sciences

$10.40-11.00 \quad$ Presentation 4: Person centered ethics and research

$11.00-11.20 \quad$ Coffee break

$11.20-11.40 \quad$ Presentation 5: Multiculturalism and bilingualism

$11.40-12.00 \quad$ Presentation 6: [Latin American perspectives]

12:00 - 12:10 Comments by special invitees.

12:10 - 13:00 Debate between speakers, commentators and audience

13:00 -13:10 Conclusions of the session

13:10 - 14:50 Lunch break

13:00 - 14:50 Organizers' executive session: Latin American Network of PCM

14:50 - 19:00 Session 2: Science and Humanism in Person Centered Clinical Care

14.50-15.10 Presentation 1: Person centered comprehensive diagnosis

$15.10-15.30 \quad$ Presentation 2: Person centered family medicine

15:30- 15:50 Presentation 3 Person centered internal medicine

15:50 -16:10 Presentation 4: Person centered surgery

16:10 - 16:30 Presentation 5: Person centered gynecology and obstetrics

16:30 - 16:50 Coffee break

16:50 - 17:10 Presentation 6: Person centered psychiatry

$\begin{array}{cl}\text { 17:10-17:30 } & \text { Presentation 7: Person centered geriatric and palliative medicine } \\ \text { 17.30 - 17:50 } & \text { Presentation 8: [Latin American perspectives] }\end{array}$

17:50 - 18:00 Comments by special invitees.

18:00 - 18:50 Debate between speakers, commentators and audience

18:50 - 19:00 Conclusions of the session

19:10 - 20:30 Special Session of the National Academy of Medicine and the National Institute of Health of Peru, and presentation of the December 2016 Peruvian Journal of Experimental Medicine and Public Health on Person Centered Medicine: From Concept to Action. 


\section{SECOND DAY: SATURDAY, DECEMEER 27, 2016}

\section{9:00 - 12:30 Session 3: Science and Humanism in Person Centered Medical}

Education

$9: 00-9.20$

$9: 20-9.40$

Presentation 1: Curricular experiments in person centered medicine

$9: 40-10.00$

Presentation 2: Methodology on communication and simulation in medical education

10:00 - 10.20

Presentation 3: Interdisciplinary professional education

$10: 20-10.40$

Presentation 4: Development of teachers and students and tutoring programs

$10.40-11.00$

Coffee break

$11.00-11.20$

Presentation 5: Student perspective on person centered medical education

$11.20-11: 30$

Presentation 6: [Latin American perspectives]

$11: 30-12: 20$

Comments by special invitees.

$12: 20-12: 30$

Debate between speakers, commentators and audience

$12: 30-14: 00$

Conclusions of the session

$14: 00-17: 30$

Noon break

$14: 00-14.20$

\section{Session 4: Science and Humanism in Person and Community Centered Public Health}

$14: 20-14.40$

$14: 40-15.00$

$15: 00-15.20$

$15: 20-15: 40$

$15: 40-16: 00$

$16: 00-16: 20$

$16.20-16: 30$

$16: 30-17: 20$

$17: 20-17: 30$

17:30-18:30 Final Session

Conclusions of the Conference

Presentation and adoption of the 2016 Lima Declaration

Upcoming activities on person centered medicine

Closing

19:00

\section{Conference dinner}

